\title{
The European Native Seed Industry: Characterization and Perspectives in Grassland Restoration
}

\author{
Marcello De Vitis 1,* (D), Holly Abbandonato ${ }^{2,3}$, Kingsley W. Dixon ${ }^{4}$, Giles Laverack ${ }^{1}$, \\ Costantino Bonomi ${ }^{2}$ and Simone Pedrini ${ }^{4}$ \\ 1 Scotia Seeds, Angus DD96TR, UK; scotiaseeds@btconnect.com \\ 2 MUSE-Science Museum, 38122 Trento, Italy; holly.abbandonato@muse.it (H.A.); \\ costantino.bonomi@muse.it (C.B.) \\ 3 Department of Earth and Environmental Sciences, University of Pavia, 27100 Pavia, Italy \\ 4 Department of Environment and Agriculture, Curtin University, Bentley 6029, Australia; \\ kingsley.dixon@curtin.edu.au (K.W.D.); simone.pedrini@postgrad.curtin.edu.au (S.P.) \\ * Correspondence: marcello.devitis@yahoo.it; Tel.: +44-7549-505-676
}

Received: 25 August 2017; Accepted: 16 September 2017; Published: 21 September 2017

\begin{abstract}
The European Union committed to restore 15\% of degraded ecosystems by 2020, and to comply with this goal, native plant material, such as seeds, is needed in large quantities. The native seed production of herbaceous species plays a critical role in supplying seed for restoration of a key ecosystem: grasslands. The objective of this work is to provide for the first time a characterization of the sector at a multi-country European level together with key information about the community of native seed users via intensive web-based research and a direct survey of industry participants. Based on more than 1300 contacts and direct surveying of more than 200 stakeholders across Europe, responses indicated that: the European native seed industry consists primarily of small to medium enterprises; responding native seed users purchase annually an average of $3600 \mathrm{~kg}$ of seeds with an average expenditure of $€ 17,600$; the industry (suppliers and consumers) favours development of seed zones and would participate in a European network for knowledge sharing. This study provides framework principles that can guide decisions in this sector, critical for fulfilling the growing demand for native seed as a primary tool for large-scale restoration on the continent.
\end{abstract}

Keywords: ecological restoration; native seed community; seed market; seed production; seed zones; stakeholder; survey

\section{Introduction}

Native seed production is a nascent but emerging specialist area that, despite the important role it plays in supplying the material needed for restoring degraded ecosystems [1], is often uncoordinated regionally and nationally. The European Union 2020 Biodiversity Strategy target to restore at least 15\% of degraded ecosystems by 2020, highlights the significance of the native seed sector as well as the need to improve the large-scale production and availability of quality native seeds. For large programs, such as these, a shortage of native plant material has been recognized as a critical limitation to carry out ecological restoration at the scale needed [1,2].

Within Europe, trade and use of herbaceous seeds are less regulated when compared to forest reproductive material [3]. More attention should be given to grasslands conservation, as they are counted among both the most species-rich vegetation types in Europe $[4,5]$ and among the most extensively degraded and least protected habitats at both the European [4] and global scale, making them identifiable as a biome at risk [6]. 
Re-seeding degraded grasslands is now a widely-used restoration method in conservation practice [7], especially for areas where spontaneous regeneration is slow, the risk of erosion is high [8] and potential propagule sources are too distant to be effective in "recolonizing" an area [7].

Native seeds are most often harvested directly from wild or semi-managed populations by public, private or non-profit enterprises who may also use this seed for growing-on, with or without selecting specific traits and creating cultivars [9]. In certain circumstances, the multiplication of native seeds for ecological restoration in a farm setting becomes necessary when harvesting large volumes of seeds directly from natural habitats would damage the reproductive capabilities of the local populations [10-12], or donor communities of sufficient size have disappeared due to human impact [13]. Moreover, sourcing local seeds and maintaining the genetic variability of the native populations is key to ecosystem conservation through improvement in long-term restoration trajectories $[3,7,11,14]$. Based on national acts occurring in a few European countries [15,16], the newly released International Standards for the Practice of Ecological Restoration [17], and other published works [2,13], restoration practitioners should avoid using seed mixtures that include non-native species, seed of unknown origin or seed sourced from genetically uniform populations. Thus reliable, local seed sources are paramount in an effective approach to regional restoration outcomes.

To implement the use of local seed origins, the geographic delineation of seed zones, within which seeds are to be collected, propagated and sown, may be critical $[18,19]$. In Europe, the first attempts to delineate national seed zones for herbaceous plants have been made only recently [19]. The definition of transnational seed zones may be crucial [2] to ensure ecological adaptation of plant species instead of the current fixation on administrative borders that often bear little relevance in an ecological or biological sense. This is highlighted by the UK's million pound, 10 year plus reintroduction program based on propagation from seed of the sole surviving lady's slipper orchid (Cypripedium calceolus) despite genetically similar, highly fecund plants occurring in large numbers just across the English Channel [20]. The advancement of seed technology such as seed priming [21] and seed coating [22], the occurrence of species-specific seed zones, the creation of new market niches for seed growers, the collaboration among researchers, seed regulatory agencies, private seed industry and public and private end users, have been recognized as political and economic challenges hindering the development of local to regional native seed programs [2].

In Europe, native plant material production seems to be limited by the high production costs and the lack of propagation/production experience [2]. In particular, the production of site-specific seed mixtures requiring pure-bred lines is significantly more expensive and riskier than for conventional seed production [23]. On the other hand, many problems in seed production, storage and use have been overcome by practice and experience, but many shortfalls in knowledge remain, which require further scientific research $[1,10]$.

In response to the knowledge gaps, several initiatives at national and international levels have initiated the process of connecting native seed stakeholders, facilitating interaction and exchange in the knowledge-production-use continuum, which is the key for improving the success of broad scale seed-based ecological restoration but frequently remains difficult [24]. Among them, the Kew UK Native Seed Hub; the Native Seed Network (www.nativeseednetwork.org) in USA; the Native Seed Science, Technology and Conservation Initial Training Network (NASSTEC; www.nasstec.eu) in Europe; and the ISTA/AOSA/SCST/Kew Wild Seed Working Group and the International Network for Seed-based Restoration (INSR; www.ser-insr.org) globally.

To our knowledge, no information about the economic value of the production sector for native and indeed herbaceous seeds at the European level is available. We chose the EU, as the existing funding framework through NASSTEC provides the platform and resources necessary to perform the requisite and extensive multi-national survey of native seed supply, demand and standards. Such data would be useful for many people in the field of production, ecological restoration, policy, as well as for potential investors and the general public, to understand the economic value of the native 
seed industry. Understanding the dynamics of native seed demand would be of particular interest in developing focused production and investment strategies for the regions.

Furthermore, a general characterization of this sector, such as the degree of development (i.e., number of native seed companies) and the structure (e.g., existence of associations of native seed producers), together with perspectives of the native seed users, would benefit practitioners and policy makers [25]. It has already been stressed that governments are in need of practical and efficient tools for ecosystem management and preservation [8].

The aim of this study is therefore to provide a snapshot of the state of the native seed community of users in Europe, with a focus on the production of herbaceous plant seeds. Here we will characterize the native seed production sector in Europe; detail the outcomes of the direct survey method for the European native seed community; and review EU funded projects covering grassland restoration as an indication of the scale required in planning for native seed utilization.

The goal of this study is to raise awareness of the challenges, needs, opinions and impacts of this community of stakeholders, as well as highlighting the potential beneficial impact for the plant material industry, local communities and, ultimately, for improving environmental outcomes.

\section{Materials and Methods}

Native seed stakeholders were assessed through a thorough web-based search using the keywords "native" and "seed" alone and combined and translated into 15 languages (Bulgarian, Croatian, Czech, Danish, Dutch, Finnish, French, German, Greek, Hungarian, Italian, Portuguese, Romanian, Slovenian, Spanish) supplemented by direct inquiries to experts in the fields of native seed science and grassland restoration in the European academic community. The contacts found were included in the native seed stakeholder list. For native seed producers, we selected the enterprises (NGOs, private or public) producing and selling seeds of native grassland plants as single species or as mixtures. The number of people working on native seed production in each enterprise was obtained through available information on the web or through direct inquiry, and was used as an indicator of the native seed production sector size. Available information on seed zones, native seed certification systems and associations of native seed producers were also obtained through the web supplemented by direct inquiries of European native seed producers, researchers and restoration practitioners.

A web-based survey was developed using SurveyMonkey (SurveyMonkey, San Mateo, CA, USA. http:/ /www.surveymonkey.com) to obtain data about European native seed stakeholders. The survey was originally prepared in English and then translated into four other languages (Spanish, French, German and Italian). A link to the survey was circulated to the contacts of the native seed stakeholder list twice (August and October 2016). The survey was also forwarded by the stakeholders themselves to other stakeholders. Nineteen questions were formulated and organized into sections: participant information (Question 1-5; Table 1), native seed market (Question 6-10; Table 1), seed zones (Question 11 and 12; Table 1), native seed standards (Question 13 and 14; Table 1) and collaboration, networking and outreach (Question 15-19; Table 1).

All questions were optional. Question 6 provided ranges in both Euros and British pounds. Similarly, Question 7 provided answers as ranges in different units (i.e., kilos, ounces, pounds). For both Questions 6 and 7, the answers were converted to Euros and kilos, respectively; then the mid-range $[(\max x+\min x) / 2]$ value was calculated for each range and the overall mean value was calculated by the following equation:

$$
\bar{x}=\sum(\text { mid }- \text { range } x \times \text { frequency } x) / n
$$

where $x$ is the range provided in the answer, frequency is the number of responses for the $x$ range, and $n$ is the total number of responses received.

Questions 15 and 16 (Table 1) considered collaboration with, and support from, the scientific community, because researchers share a common language (scientific English), have contacts with 
many different stakeholders, and have access to international literature, so they may represent a bridge between different stakeholder categories and facilitate knowledge transfer. The answer frequencies were calculated using Microsoft Excel (2010). Given the possibility that different categories may have different perspectives, in some cases, answer frequencies were calculated by category.

Table 1. Questions formulated for the native seed community survey and total response ( $n$ ) for each question.

\begin{tabular}{llc}
\hline & \multicolumn{1}{c}{ Questions } & $n$ \\
\hline Question 1 & Which sector are you working in? & 215 \\
Question 2 & Which of the following best describes your current profession? & 215 \\
Question 3 & In which country is your profession or your main affiliation based? & 216 \\
Question 4 & Which species do you work with? & 188 \\
Question 5 & Do you use native seeds for your work? & 174 \\
Question 6 & On average, approximately how much do you spend on purchasing native seeds each year? & 77 \\
Question 7 & Which amount of native seeds do you buy or sell per year? & 83 \\
Question 8 & Which action related to native seeds or restoration is the most expensive for you? & 119 \\
Question 9 & Which category do your major customers belong to? & 81 \\
Question 10 & Is the demand for native plant material over the last 10 years increasing, & 136 \\
Question 11 & Are you in favor of the development of seed zones? & 123 \\
Question 12 & If a standard method is used, should seed zones cross country boundaries? & 122 \\
Question 13 & Do you use external protocols/guidelines for any of the following activities such as seed & 99 \\
Question 14 & collection, cleaning, storage and treatment? & 48 \\
Question 15 & Do you have an active dialogue/collaboration with any academic/research institutes? & 112 \\
Question 16 & If no, would you like to have the scientific support of an academic/research institute? & 22 \\
Question 17 & If a trade association of native seed producers existed both at the European and national & 114 \\
& level, which one would you join? & 113 \\
Question 18 & Would you like to join a European online network to find other people who use native seeds & 113 \\
Question 19 & to share material, knowledge and resources? & 115 \\
\hline
\end{tabular}

The EU's funding frameworks covering environmental protection and restoration are the ERDF (European Regional Development Fund), the EAFRD (European Agricultural Fund for Rural Development) and the LIFE program, EU's main funding instrument for environment and climate action. For the purpose of this study, only the LIFE program was considered because, through the LIFE Project Database of the Environment Department of the European Commission website (http:/ / ec.europa.eu/environment/life/project/Projects/index.cfm), it is possible to obtain details on specific projects. In particular, the LIFE Project Database was queried for projects financed between 2004 and 2014 containing the keywords "grassland ecosystem" and "restoration measure". The list of projects was filtered, selecting those in which active grassland restoration was among the objectives. For these projects, funding year, lead partner country, duration, total budget, European contribution, and ha of habitat restored/to be restored were recorded. Finally, the total LIFE budgets funded during the 2007-2013 and 2014-2020 periods were compared.

\section{Results}

\subsection{Identification of European Native Seed Stakeholders and Characterization of the Native Seed Industry in Europe}

A total of 1342 contacts from 31 European countries were assessed, both institutional (66\%) and personal $(34 \%)$, including categories such as botanical gardens, ecological consultants, governmental and local bodies for nature conservation, laboratories for seed testing and conservation, landscape contractors, native seed producers, non-governmental organizations (NGOs), nurseries, research institutes and restoration practitioners.

A total of 100 native seed producers from 21 countries were found (Table 2) with a prevalence of private companies. 
Table 2. For the countries where native seed producers of herbaceous plants were identified ${ }^{1}$, the number is reported, specifying if they are NGO, private or public enterprises. Where they occur, the number of seed zones (SZ) are also reported.

\begin{tabular}{|c|c|c|c|c|c|}
\hline \multirow{2}{*}{ Country } & \multicolumn{4}{|c|}{ Native Seed Producers } & \multirow{2}{*}{$\mathrm{SZ}^{2}$} \\
\hline & NGO & Private & Public & Total & \\
\hline Austria & 1 & 9 & & 10 & 10 \\
\hline Belgium & & 3 & & 3 & \\
\hline Bulgaria & & 2 & & 2 & \\
\hline Czech Republic & & 3 & & 3 & 5 \\
\hline Denmark & & 2 & & 2 & \\
\hline France & & 6 & & 6 & 11 \\
\hline Germany & & 12 & & 12 & 22 \\
\hline Greece & & & 1 & 1 & \\
\hline Hungary & & 2 & & 2 & \\
\hline Iceland & & & 1 & 1 & \\
\hline Italy & & 4 & 1 & 5 & \\
\hline The Netherlands & & 4 & & 4 & \\
\hline Norway & & 2 & 1 & 3 & 4 \\
\hline Poland & & 2 & & 2 & \\
\hline Portugal & & 2 & 1 & 3 & \\
\hline Republic of Ireland & & 2 & & 2 & \\
\hline Romania & & 2 & & 2 & \\
\hline Spain & & 10 & & 10 & \\
\hline Sweden & & 3 & & 3 & \\
\hline Switzerland & & 12 & & 12 & 11 \\
\hline UK & 1 & 11 & & 12 & 24 \\
\hline Tot. & 2 & 93 & 5 & 100 & \\
\hline
\end{tabular}

${ }^{1}$ Some producers were not verified if actually producing native seeds from local populations and if following recognized guidelines. ${ }^{2}$ Sources. Austria [26]; Czech Republic [27]; France [28]; Germany [29]; Great Britain: seed zones were developed for tree species [30] but they are used by herb seed producers too; Norway: four seed zones are suggested on the basis of genetic analysis on six species [8]; Switzerland [31].

The highest numbers (6-12) of native seed producers occurred in Central Europe (Austria, Germany and Switzerland), France, Spain and UK; in most of the other countries, the number of companies was between one and three (Table 2). Across 27 native seed enterprises from 15 countries, the total number of people working in native seed production was 166 with an average of $6.1 \pm 8.3$ (mean \pm standard deviation) persons, with the majority employing 1-3 workers (Figure 1). Through correspondence with these companies, we also found that in a quarter of cases (25\%) seed collection and multiplication was carried out by contracted seasonal staff or farmers.

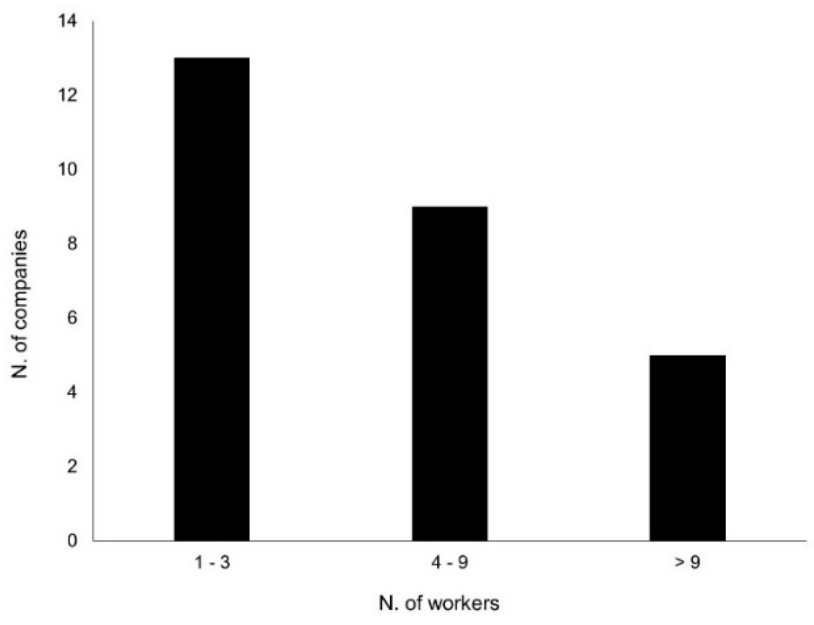

Figure 1. Class frequency for the number of workers in native seed production across 27 herbaceous seed producers in 15 European countries. 
Associations of native seed producers and native seed certification systems were found in two (Austria and Germany) and three countries (Austria, Germany and France), respectively, while seed zones were identified in seven countries (Figure 2; Table 2).

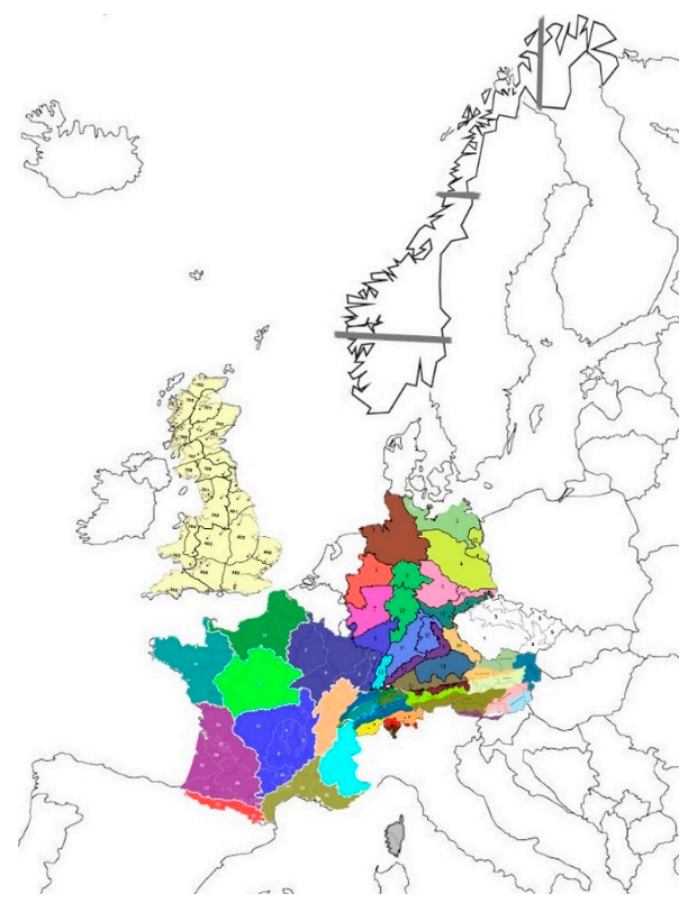

Figure 2. National seed zones currently available in Europe. Sources: Austria [24]; Czech Republic [25]; France [26]; Germany [27]; Great Britain [28]; Norway [8]; Switzerland [29].

\subsection{A Survey of the Native Seed Community}

\subsubsection{Participant Information}

Two-hundred and sixteen responses were received from 20 countries, of which the majority (77\%) came from five countries (UK, France, Germany, Italy and Spain, in decreasing order). For the purpose of this study, responses to Questions 4 and 5 were filtered to exclude forestry seed users, narrowing the selection to users of native seeds of herbaceous plants (148 responses from 16 countries). These respondents were mostly $(49.6 \%$ ) from the public sector, with $35.4 \%$ from the private sector, and $15.0 \%$ from NGOs; and belonged to 14 different professional categories with research, native seed production, and restoration practice being the most represented, followed by seed analysis and conservation, consultancy, nursery, administration, policy, gardening and landscape contracting (Table S1).

\subsubsection{Native Seed Market}

For Questions 6 and 7, the response rates are reported in Table 3.

From these data, it was possible to estimate that a single user responding to the survey (individual or entity) purchases on average $3616 \mathrm{~kg}$ of native seeds and expends 17,599 Euros annually (Table 3), for a total of 1,355,139 Euros and 300,115 kg of native seeds purchased annually across 77-83 users (Note: because the two questions are unrelated it was not possible to derive the median price per $\mathrm{kg}$ of seed).

The most expensive activity for $30.0 \%$ of the native seed producers $(n=20)$ was the field management before crop multiplication, followed by harvesting seed from crops $(20.0 \%)$, seed collection from the population of origin and seed purchasing (both 15.0\%; Figure 3). 
Table 3. Range, mid-range, frequency, total and mean values regarding native seed users' expenditure $(€)$ and quantity traded $(\mathrm{kg})$ per year.

\begin{tabular}{|c|c|c|}
\hline Range & Mid-Range & Frequency \\
\hline \multicolumn{3}{|l|}{ Expenditure $(€)$} \\
\hline $1-100$ & 50.5 & 26 \\
\hline $101-5000$ & 2550.5 & 26 \\
\hline $5001-10,000$ & 7500.5 & 7 \\
\hline $10,001-100,000$ & $55,000.5$ & 17 \\
\hline $100,001-500,000$ & $300,000.5$ & 1 \\
\hline$>500,000$ & $500,000^{1}$ & 0 \\
\hline Total & & 77 \\
\hline Mean & \multicolumn{2}{|c|}{$17,599.2$} \\
\hline \multicolumn{3}{|l|}{ Traded quantity (kg) } \\
\hline $0.01-0.1$ & 0.055 & 8 \\
\hline $0.2-1$ & 0.6 & 11 \\
\hline $2-10$ & 6 & 21 \\
\hline $11-100$ & 55.5 & 12 \\
\hline $101-500$ & 300.5 & 6 \\
\hline 501-1000 & 750.5 & 8 \\
\hline $1001-10,000$ & 5500.5 & 13 \\
\hline $10,001-100,000$ & $55,000.5$ & 4 \\
\hline$>100,000$ & $100,000^{1}$ & 0 \\
\hline Total & \multirow{2}{*}{\multicolumn{2}{|c|}{3615.8}} \\
\hline Mean & & \\
\hline
\end{tabular}

${ }^{1}$ For these classes, the minimum value was taken as mid-range.

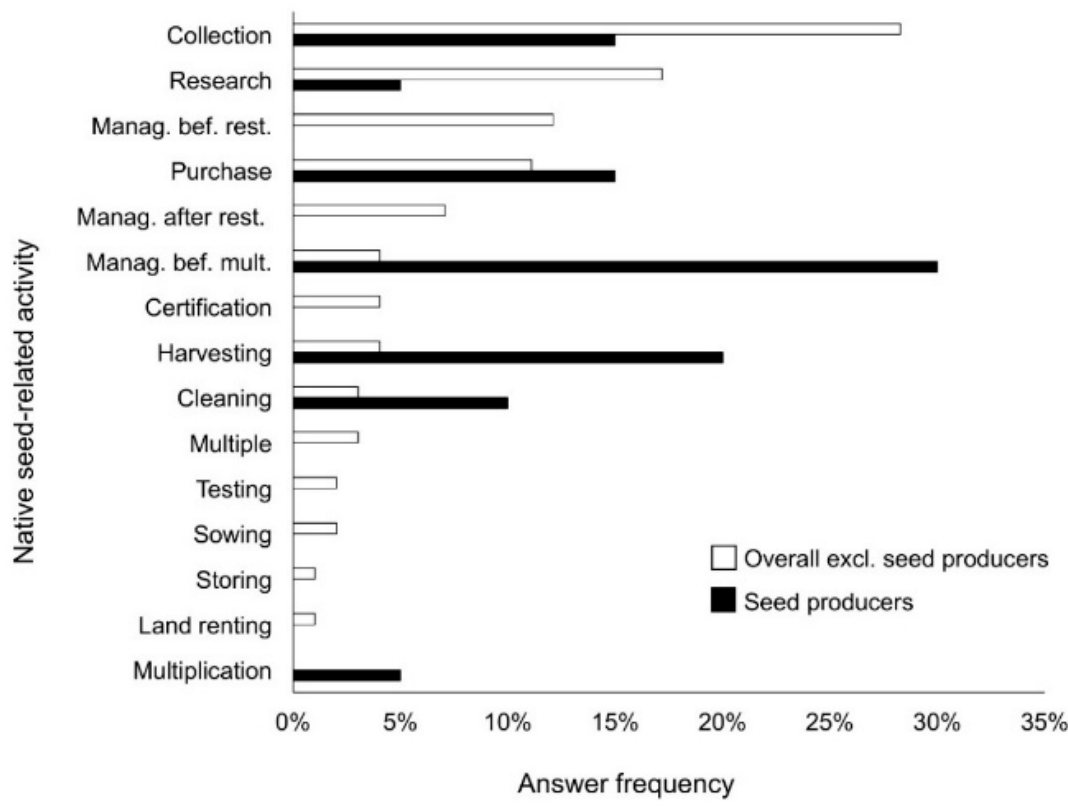

Figure 3. Perceived costliness of seed-related activities. Answer frequency of respondents to Question 8 "Which action related to native seeds or restoration is the most expensive for you?" The answers by native seed producers $(n=20)$ and the remainder of the community (overall excluding seed producers; $n=99$ ) are shown. Some of the choices reported in the graph are abbreviations of the options available in the survey: seed collection from the population of origin; site management before restoration; site management after restoration; field management before crop multiplication (e.g., ploughing, weeding, and application of fertilizers); harvesting seed from crops; land renting/contract growing for crop multiplication. 
The top four responses for the remainder of respondents, excluding seed producers $(n=99)$, were: seed collection from the population of origin $(28.3 \%)$, research $(17.2 \%)$, site management before restoration $(12.1 \%)$, and seed purchasing $(11.1 \%)$. When users were questioned about their major customers, 81 responses were received, but for the purpose of this work, only those from native seed suppliers $(n=21)$ were considered, with the top three customer categories being land contractors $(29.0 \%)$, individuals and governmental bodies $(19.0 \%$ each), followed by retailers and nurseries (Figure 4).

The answers to Question $10(n=136)$, relate to the state of the native plant material demand in the last decade, and were sorted based on native plant material suppliers (seed producers + nurseries; $n=27)$ and the remainder of the native seed community $(n=109)$. The majority of the native seed community $(75.2 \%)$ perceived an increase in demand, $12.8 \%$ felt it was stable, $10.2 \%$ stated a level of uncertainty, while $1.8 \%$ reported a decline. A similar trend was detected in the responses provided by the native plant material suppliers (increase: $74.1 \%$; stable: $11.1 \%$; uncertain: $11.1 \%$; and decline: $3.7 \%$ ).

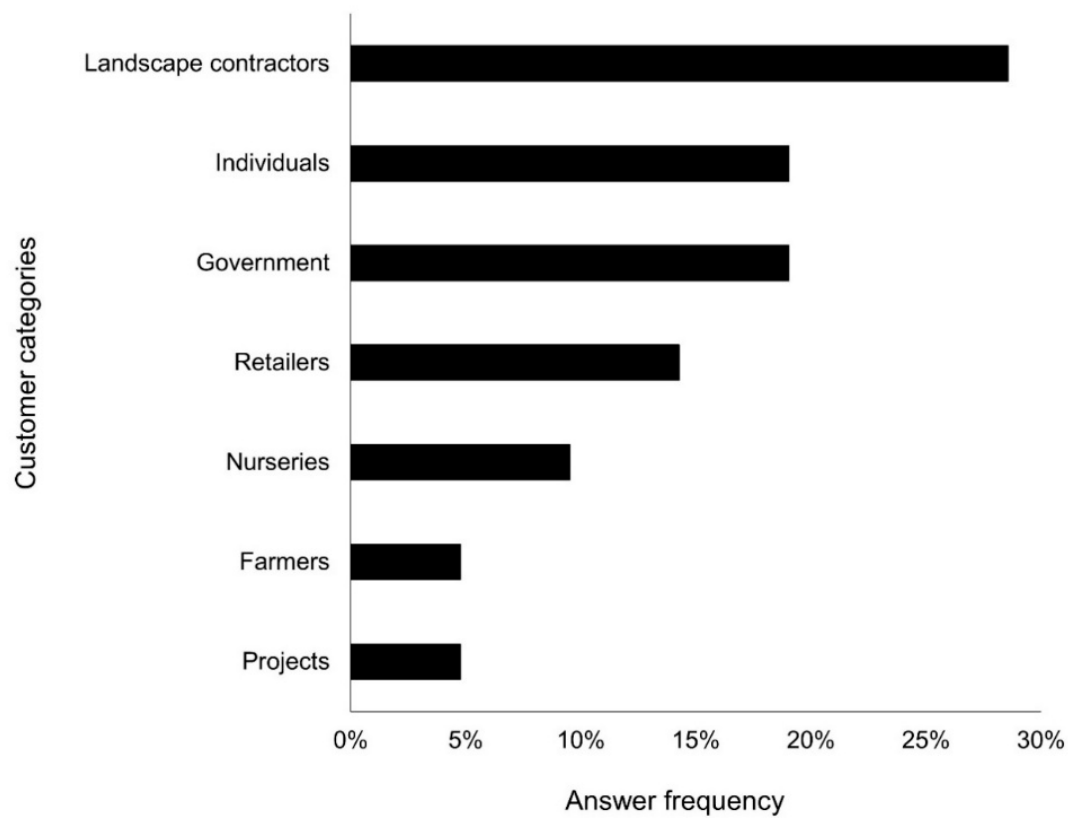

Figure 4. Answer frequencies to question 9 "Which category do your major customers belong to?" by native seed producers $(n=21)$.

\subsubsection{Seed Zones}

Most of the overall native seed community $(73.2 \% ; n=123)$, as most of the researchers $(81.4 \%$; $n=43)$ and producers $(64.7 \% ; n=17)$, expressed support towards the development of seed zones, while a minority of groups were not in favour or unsure. Again, the majority of the respondents $(62.3 \%$; $n=122)$ were in favour of trans-national boundaries for seed zones, both from the research $(68.2 \%$; $n=44)$ and production $(70.6 \% ; n=17)$ sectors.

\subsubsection{Native Seed Standards}

The respondents were divided when questioned about the adoption of "external" quality and handling guidelines (Yes: $54.5 \%$; No: $45.5 \%$ ). The participants who responded positively were asked to provide the name of these guidelines/protocols and if they would amend them to match native seed requirements. The listed guidelines included: ENSCONET (European Native Seed Conservation Network), listed nine times by users from seven different countries; ISTA (International Seed Testing Association) by eight users from four different countries; APAT (Agency for Environmental Protection and Technical Services) four times by Italian and Spanish users; VWW (Association of German Wild 
Seed and Wild Plant Producers) by four German users; Flora Locale (https: / www.floralocale.org) three times by users from the UK and Republic of Ireland; with FAO, Royal Botanic Gardens of Kew, Forestry Commission, and GZert guidelines referred to by one or two users. The majority $(64.6 \%)$ of the respondents did adapt those guidelines to be relevant to their native seeds. Among the native seed producers $(n=20), 70.0 \%$ were positive about the use of external protocols, and less than half $(41.7 \%)$ of these respondents said they did modify the protocols to match native seed requirements, though it is unclear as to why.

\subsubsection{Collaboration and Outreach}

The majority of the overall native seed community $(76.8 \% ; n=82$, without the category "researchers") reported an active collaboration or dialogue with a research institute (question 15) with similar values $(80.0 \%)$ conveyed by native seed producers $(n=20)$. Respondents without active collaboration with a research institute expressed the will to engage with academia in $81.8 \%$ of the overall native seed community and $75.0 \%$ of native seed producers.

For question 17, there were 114 responses. However, we took into consideration only native seed producers $(n=20)$ as we specifically asked about "a trade association of native seed producers". Six producers $(30.0 \%)$ would support such a national association, three $(15.0 \%)$ a Europe-only association, nine (45.0\%) both a national and European association, and for two (10.0\%) respondents the question was non-applicable. Finally, the vast majority $(82.6 \%)$ of the native seed community would join a European network to connect with other native seeds users and $74.3 \%$ undertook outreach activities to promote the use of native plant materials.

\subsection{EU Funding for Grassland Rrestoration}

Interrogation of the LIFE project Database produced 52 results. Of these projects, 30, coordinated by 15 different countries, were considered, as they indicated in their objectives, the direct restoration of grassland habitat. The total area of grassland habitat under or proposed for restoration represented an 18-year period (the duration of the selected projects was between 2004 and 2022) totalling 16,174 ha, ranging between 15 and 4439 ha attributable to single projects. For these projects, the EU contribution was over half of the total budget ( $58 \pm 11 \%$; mean \pm standard deviation). The total expenditure in the decade 2004-2014 for these projects was $€ 102.55$ million, ranging between $€ 412,891$ and $€ 9,587,813$ per single project (Figure 5).

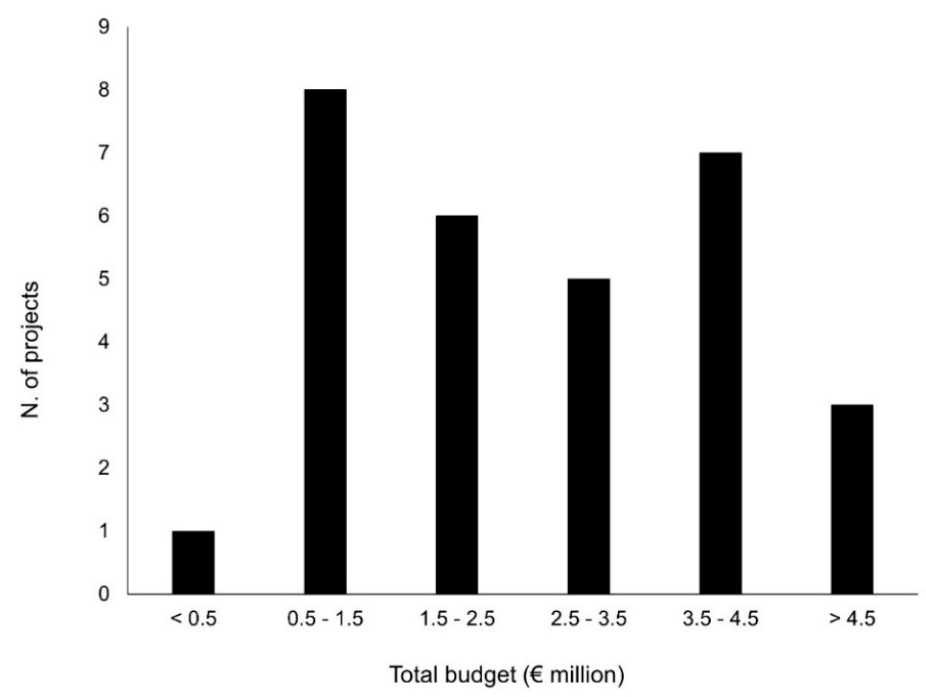

Figure 5. Total budget for grassland restoration projects funded in the decade 2004-2014 through the EU LIFE program $(n=30)$. 
The fourth phase of the LIFE program ran from 2007 to 2013 with a budget of $€ 2.14$ billion [32] while in the new LIFE Programme (2014-2020), which aims to achieve 5\% of ecosystem services restored and to improve the conservation status of $25 \%$ of target habitats and species, $€ 3.40$ billion is allocated [32]), an increase of $59 \%$ over the previous period.

\section{Discussion}

This is the first multinational study to characterize the native seed production sector with an emphasis on ecological restoration in Europe. This study is comprehensive as respondents included small, private businesses in countries (e.g., Hungary, Italy, The Netherlands, Norway, Sweden) that are not part of the main European spoken languages (i.e., English, Spanish, French, German).

The native seed companies found during this study were the most likely to contribute to ecological restoration because they were known or reported by other stakeholders, such as researchers, practitioners and other companies.

The degree of development of the native seed industry in Europe focused on herbaceous plants seems to be related to the need for grassland restoration across the continent. In north-western and Central European countries (e.g., Great Britain, France and Germany), where, in the last decades, the phenomenon of species-rich grassland decline particularly occurred, due to intensive agricultural management [13], we found the highest numbers of companies and the largest as assessed by the number of employees.

Since most of the surveyed companies employed 1-9 workers, we assume that they belong to the category of SMEs (small- and medium-size enterprises) and family-run/owner-operator businesses.

In most European countries, there are no controls on seed movement (e.g., seed zones), mechanisms to support the producers (e.g., associations), and processes that value native over non-native seed (e.g., certification systems). However, with the advent of the International Standards for the Practice of Ecological Restoration [17], locally sourced seed based on a local reference community is an expected component in achieving full recovery (i.e., restoration) of an ecosystem.

Although guidelines for the movement of herbaceous seeds are available at national level only in seven European countries (Austria, Czech Republic, France, Germany, Great Britain, Norway, and Switzerland), the majority of the European native seed community agreed with the development of seed zones that reflect ecological rather than geopolitical boundaries. The development of such zones would enlarge seed catchment opportunities and lead to new economic development opportunities within Europe, including assisting in rural industry diversification.

There may be a link between the presence of associations of native seed producers and a seed certification system (Austria and Germany), with the association being involved in developing the certification system. This means that creating an association of producers may be a crucial step in developing a certification system. Developing a national seed association or activating an existing association to develop seed certification represents a vital next step in harmonizing European native seed standards. Indeed, respondents showed great interest in being part of a network aimed at knowledge sharing. The International Network for Seed-Based Restoration (INSR; http:/ /www.serinsr.org), a thematic section of the Society for Ecological Restoration, represents one opportunity since it brings together native seed stakeholders and shares existing knowledge on native seed with the aim of promoting and enhancing seed-based solutions in restoration. The US Native Seed Network and National Seed Strategy are a stand-out example of a national approach to the generation and use of native seed. The Network (http:/ /nativeseednetwork.org/) is an online platform for both restoration practitioners and native seed producers that provides search tools (e.g., seed search and selection) and information on all aspects of native seeds. The Strategy is an overarching plan formulated by a coalition of federal agencies, non-profit organizations and private sector businesses with the aim of ensuring the availability of genetically appropriate seed reserves to restore viable, productive plant communities and sustainable ecosystems [33]. 
In Europe, the major purchasers of native plant seeds were found to be landscape contractors, single individuals, governmental bodies, retailers and nurseries, in order of relevance for native seed suppliers. Seed collection was found to be one of the most expensive activities related to the seed production to restoration chain, according to our survey and to previous reports [34], making it a potential economic constraint and where a focus on technology development would yield significant economic benefits. For native seed producers, other most expensive activities were related to field labour, such as field preparation for crop multiplication and seed harvesting which, for some species, is still conducted by hand, as it results in higher seed quality [35].

Our data provided the first estimation, albeit rough, of quantities of and expenditure on native seeds on a yearly basis by European users. So far, quantitative data on quantities and/or expenditures were provided only for Austria (potential need of site-specific mixtures of alpine seeds for alpine meadow restoration $=200$ metric tons annually) [23], Germany (market turnover of $€ 12 \mathrm{M}$ and native seed sold annually = ca. 200 metric tons; source: http:/ / ser-insr.org/webinars / 2016/11/17/nativeseed-production-in-germany); and the UK (overall native seed market $=70-120$ metric tons and $£ 5-6 \mathrm{M}$, with expected growth to $120-240$ metric tons and $£ 6-17 \mathrm{M}$ by 2019-2020) [36]. All evidence points to demand for herbaceous native seed in the region to be increasing, e.g., expansion of the EU's LIFE program.

The present study revealed that the majority of European native seed companies, and of the overall native seed community, has established links with research institutes or was willing to do so. This is promising in terms of advancing native seed standards and in the improvement of the pool of species available from seed suppliers, which imposes a critical biodiversity filter in ecological restoration projects ("restoration species pool" sensu [37]). Seed growers are often reluctant to take on new species because of production and marketing uncertainties [2], and, as shown by our survey, the community working with native seeds often needs to modify existing protocols including collection, cleaning, storage and treatment to match native plant requirements. Collaboration with researchers and technologists may play a key role in improving guidelines and finding solutions for production of difficult grassland species [37].

In Europe, inadequacy in native seed supply to meet current and emerging demand may result from the lack of appropriate production planning, statutory recognition and protection for native seed collection, production and trade, which in turn may limit the market for native seeds and facilitate the use of cheap seed mixtures of ecologically unsuitable species [23]. Adequate planning would harmonize production to meet seed demand. However, achieving this goal will require improved and facilitated communication between users and producers. Importantly, providing a sound regulatory framework covering native seeds, together with incentives from the EU, local governments and the communities will ensure the native seed industry develops in a way that is economically and ecologically sustainable.

In Germany, one of the most advanced European countries in native seed production and grassland restoration, the Federal Nature Conservation Act [15] requires that from 2020, all restoration of natural areas requires the use of native seed. The German Association of wild seed and wild plant producers (VWW; http:/ / www.natur-im-vww.de/) calculated that, to comply with this requirement, 2000 metric tons of native seeds would be needed by 2020, that will require tenfold increase in production over the next four years [38]). However, this national aspiration contradicts the legal constructs under EU Directives (see [39]: Commission Directive 2010/60/EU, art. 8 "quantitative restriction") that limits the maximum value of native seed to $5 \%$ of the fodder species market. In Europe, as it has been already stressed in US [33], the policy directives should shift away from agronomic towards ecological models if we are to meet the needs of restoration on the scale required in the coming century. 


\section{Conclusions}

As demand grows for knowledge-informed policy decisions in environmental issues [40], the creation of a European native seed network/association is pivotal to developing effective production and deployment strategies. Such a network could be charged with ensuring the accuracy and adequacy of knowledge transfer to decision-makers, contributing to policy frameworks that support the expansion of the native seed industry in Europe. Importantly, such a network would lead to a united voice and provide impetus for the harmonization of seed policies across Europe.

We believe that in this age of restoration, in Europe as for other countries around the world, greater attention should be focused on the emerging native seed production sector, supported by robust regulatory processes that promote, enhance and provide incentives for the use of native plant material. In order to achieve positive and successful outcomes, a vibrant, diverse native seed community is essential to ensure that collective wisdom leads to the most cost effective and enduring outcomes for improving nature and natural environments.

Supplementary Materials: The following are available online at www.mdpi.com/2071-1050/9/10/1682/s1, Table S1: Number of responses for each question of the survey, reported by category of respondents.

Acknowledgments: The authors are grateful to C. Blandino, E. Fernández-Pascual, R. Fiegener, S. Frischie, F. Guest, P.P.M. Iannetta, E. Ladouceur, M. Marin and C. Trivedi for valuable comments on the survey draft; to E. Fernández-Pascual, S. Frischie, J. Schneider, M. Tudela Isanta, V. Carrier for the translations of the survey; and to H.W. Pritchard for useful comments to improve the manuscript. The research leading to these results received funding from the People Programme (Marie Curie Actions) of the European Union's Seventh Framework Programme FP7/2007-2013/ under REA grant agreement No. 607785.

Author Contributions: Marcello De Vitis, Holly Abbandonato, Giles Laverack, Costantino Bonomi and Simone Pedrini conceived the study; Marcello De Vitis and Holly Abbandonato gathered international contacts, and designed and circulated the survey; Marcello De Vitis collected and analysed the data and wrote the paper; Holly Abbandonato, Kingsley W. Dixon, Giles Laverack, Costantino Bonomi and Simone Pedrini provided substantial editing and revision to the manuscript draft. All authors have read and approved the final manuscript.

Conflicts of Interest: The authors declare no conflict of interest. The founding sponsors had no role in the design of the study; in the collection, analyses, or interpretation of data; in the writing of the manuscript, and in the decision to publish the results.

\section{References}

1. Merritt, D.J.; Dixon, K.W. Restoration seed banks-A matter of scale. Science 2011, 332, 424-425. [CrossRef] [PubMed]

2. Tischew, S.; Youtie, B.; Kirmer, A.; Shaw, N. Farming for restoration: building bridges for native seeds. Ecol. Restor. 2011, 29, 219-222. [CrossRef]

3. Vander Mijnsbrugge, K.; Bischoff, A.; Smith, B. A question of origin: Where and how to collect seed for ecological restoration. Basic Appl. Ecol. 2010, 11, 300-311. [CrossRef]

4. EEA. EU 2010 Biodiversity Baseline; EEA Technical Report No 12/2010; European Environment Agency: Copenhagen, Denmark, 2010.

5. Wilson, J.B.; Peet, R.K.; Dengler, J.; Pärtel, M. Plant species richness: The world records. J. Veg. Sci. 2012, 23, 796-802. [CrossRef]

6. Hoekstra, J.M.; Boucher, T.M.; Ricketts, T.H.; Roberts, C. Confronting a biome crisis: Global disparities of habitat loss and protection. Ecol. Lett. 2005, 8, 23-29. [CrossRef]

7. Török, P.; Vida, E.; Deák, B.; Lengyel, S.; Tóthmérész, B. Grassland restoration on former croplands in Europe: An assessment of applicability of techniques and costs. Biodivers. Conserv. 2011, 20, 2311-2332. [CrossRef]

8. Jørgensen, M.H.; Elameen, A.; Hofman, N.; Klemsdal, S.; Malaval, S.; Fjellheim, S. What's the meaning of local? Using molecular markers to define seed transfer zones for ecological restoration in Norway. Evol. Appl. 2016, 9, 673-684. [CrossRef] [PubMed]

9. Chivers, I.H.; Jones, T.A.; Broadhurst, L.M.; Mott, I.W.; Larson, S.R. The merits of artificial selection for the development of restoration-ready plant materials of native perennial grasses. Restor. Ecol. 2016, 24, $174-183$. [CrossRef] 
10. Laverack, G.; Matthews, S.; Powell, A.A.; Khajeh Hosseini, M. Scottish wildflower seeds: Production and use. Bot. J. Scotl. 2006, 58, 49-58. [CrossRef]

11. Broadhurst, L.M.; Lowe, A.; Coates, D.J.; Cunningham, S.A.; McDonald, M.; Vesk, P.A.; Yates, C. Seed supply for broadscale restoration: Maximising evolutionary potential. Evol. Appl. 2008, 1, 587-597. [CrossRef] [PubMed]

12. Meissen, J.C.; Galatowitsch, S.M.; Cornett, M.W. Risks of overharvesting seed from native tallgrass prairies. Restor. Ecol. 2015, 23, 882-891. [CrossRef]

13. Kiehl, K.; Kirmer, A.; Donath, T.W.; Rasran, L.; Hölzel, N. Species introduction in restoration projects-Evaluation of different techniques for the establishment of semi-natural grassland in Central and Northwestern Europe. Basic Appl. Ecol. 2010, 11, 285-299. [CrossRef]

14. Manchester, S.J.; McNally, S.; Treweek, J.R.; Sparks, T.H.; Mountford, J.O. The cost and practicality of techniques for the reversion of arable land to lowland wet grassland-An experimental study and review. J. Environ. Manag. 1999, 55, 91-109. [CrossRef]

15. BNatSchG. Act on Nature Conservation and Landscape Management (Federal Nature Conservation Act-BNatSchG) of 29 July 2009; Federal Law Gazette; Federal Ministry for the Environment, Nature Conservation, and Nuclear Safety: Berlin, Germany, 2010; p. 2542. Available online: http:/ / www.bmub.bund.de/fileadmin/ Daten_BMU/Download_PDF/Naturschutz/bnatschg_en_bf.pdf (accessed on 24 August 2017).

16. Norwegian Nature Diversity Act. 2009. Available online: https://lovdata.no/dokument/NL/lov/2009-0619-100?q=naturmangfoldloven (accessed on 6 September 2017).

17. McDonald, T.; Jonson, J.; Dixon, K.W. National standards for the practice of ecological restoration in Australia. Restor. Ecol. 2016, 24, S4-S32. [CrossRef]

18. Nevill, P.G.; Tomlinson, S.; Elliott, C.P.; Espeland, E.K.; Dixon, K.W.; Merritt, D.J. Seed production areas for the global restoration challenge. Ecol. Evol. 2016, 6, 7490-7497. [CrossRef] [PubMed]

19. Durka, W.; Michalski, S.G.; Berendzen, K.W.; Bossdorf, O.; Bucharova, A.; Hermann, J.; Hölzel, N.; Kollmann, J. Genetic differentiation within multiple common grassland plants supports seed transfer zones for ecological restoration. J. Appl. Ecol. 2017, 54, 116-126. [CrossRef]

20. Dixon, K.W.; Kell, S.P.; Barrett, R.L.; Cribb, P.J. Orchid Conservation, 1st ed.; Natural History Publications (Borneo), Kota Kinabalu: Sabah, Malaysia, 2003; ISBN $9838120782 / 9789838120784$.

21. Paparella, S.; Araújo, S.S.; Rossi, G.; Wijayasinghe, M.; Carbonera, D.; Balestrazzi, A. Seed priming: State of the art and new perspectives. Plant Cell Rep. 2015, 34, 1281-1293. [CrossRef] [PubMed]

22. Pedrini, S.; Merritt, D.J.; Stevens, J.; Dixon, K. Seed coating: Science or marketing spin? Trends Plant Sci. 2017, 22, 106-116. [CrossRef] [PubMed]

23. Krautzer, B.; Graiss, W.; Blschka, A. Seed production of site-specific grasses and herbs in Austria. In Proceedings of the 7th European Conference on Ecological restoration, Avignon, France, 23-27 August 2010; Society for Ecological Restoration: Washington, DC, USA.

24. Görg, C.; Wittmer, H.; Carter, C.; Turnhout, E.; Vandewalle, M.; Schindler, S.; Livorell, B.; Lux, A. Governance options for science-policy interfaces on biodiversity and ecosystem services: Comparing a network versus a platform approach. Biodivers. Conserv. 2016, 25, 1235-1252. [CrossRef]

25. Wheaton, J.M.; Darby, S.E.; Sear, D.A.; Milne, J.A. Does scientific conjecture accurately describe restoration practice? Insight from an international river restoration survey. Area 2006, 38, 128-142. [CrossRef]

26. REWISA, V. Prüfrichtlinie für die Gewinnung und den Vertrieb von Regionalen Wildgräsern und Wildkräutern $\left(R E W I S A^{\circledR}\right)$; Lehr- und Forschungszentrum für Landwirtschaft Raumberg-Gumpenstein: Irdning, Austria, 2010. Available online: http:/ / www.rewisa-netzwerk.at/Naturgarten/files/8c/8cbe2495-95bc-44d3-832bd7060dbb9944.pdf (accessed on 24 August 2017).

27. Ševčíková, M.; Jongepierová, I.; Prach, K. Standardy péče o př́rodu a Krajinu. Available online: http:/ / standardy.nature.cz/res/archive/162/021148.pdf?seek=1400575046 (accessed on 24 August 2017).

28. Fédération des Conservatoires Botaniques Nationaux. Référentiel Technique-Associé au Règlement D'usage de la Marque Collective Simple Végétal Local. Edition du 07/11/14. 2014. Available online: http:/ /www. fcbn.fr/sites/fcbn.fr/files/ressource_telechargeable/referentiel_technique_vlocal_vf_0.pdf (accessed on 24 August 2017). 
29. Prasse, R.; Kunzmann, D.; Schröder, R. Entwicklung und Praktische Umsetzung Naturschutzfachlicher Mindestanforderungen an Einen Herkunftsnachweis für Gebietseigenes Wildpflanzensaatgut Krautiger Pflanzen; Institute for Environmental Planning of the Gottfried Wilhelm Leibniz Universität: Hannover, Germany, 2010. Available online: https://www.dbu.de/OPAC/ab/DBU-Abschlussbericht-AZ-23931.pdf (accessed on 24 August 2017).

30. Forestry Commission. Regions of Provenance and Native Seed Zones. Available online: https://www. forestry.gov.uk/forestry/infd-72kldl (accessed on 24 August 2017).

31. SKEW. Empfehlungen für den Anbau und Die Verwendung von Pflanz-Und Saatgut Einheimischer Wildpflanzen; Sekretariat SKEW: Nyon, Switzerland, 2009. Available online: https:/ / www.infoflora.ch/de/assets/content/ documents/recommandations_pltes_sauvages_D_F/Empf_WiWildpflanz.pdf (accessed on 24 August 2017).

32. The LIFE Programme. Available online: http://ec.europa.eu/environment/life/about/\#evaluation (accessed on 24 August 2017).

33. Oldfield, S.; Olwell, P. The right seed in the right place at the right time. BioScience 2015, 65, 955-956. [CrossRef]

34. Tucker, G.; Underwood, E.; Farmer, A.; Scalera, R.; Dickie, I.; McConville, A.; van Vliet, W. Estimation of the Financing Needs to Implement Target 2 of the EU Biodiversity Strategy; Report to the European Commission; Institute for European Environmental Policy: London, UK, 2013. Available online: http:/ / ec.europa.eu/ environment/nature/biodiversity/comm2006/pdf/2020/Fin\%20Target\%202.pdf (accessed on 24 August 2017).

35. Marin, M.; Toorop, P.; Powell, A.A.; Laverack, G. Tetrazolium staining predicts germination of commercial seed lots of European native species differing in seed quality. Seed Sci. Technol. 2017, 45, 151-166. [CrossRef]

36. UK Native Seed Hub. Royal Botanic Gardens, Kew, UK Native Seed Hub Initiative, 10 Year Business Plan; Chris Blandford Associates: London, UK, 2011. Available online: https://www.kew.org/sites/default/files/UK\% 20Native\%20Seed\%20Hub\%2010\%20Year\%20Business\%20Plan.pdf (accessed on 24 August 2017).

37. Ladouceur, E.; Jiménez-Alfaro, B.; Marin, M.; de Vitis, M.; Abbandonato, H.; Iannetta, P.P.M.; Bonomi, C.; Pritchard, H.W. Native seed supply and the ecological restoration species pool. Conserv. Lett. 2017. [CrossRef]

38. Native Seed Production in Germany. The International Network for Seed-based Restoration. Available online: http://ser-insr.org/webinars/2016/11/17/native-seed-production-in-germany (accessed on 19 September 2017).

39. European Commission. Commission Directive 2010/60/EU of 30 August 2010 providing for certain derogations for marketing of fodder plant seed mixtures intended for use in the preservation of the natural environment. Off. J. Eur. Union 2010, 228, 10-14. Available online: http:/ / eur-lex.europa.eu/legal-content/ EN/TXT/PDF/?uri=CELEX:32010L0060\&from=EN (accessed on 24 August 2017).

40. Nesshöver, C.; Livoreil, B.; Schindler, S.; Vandewalle, M. Challenges and solutions for networking knowledge holders and better informing decision-making on biodiversity and ecosystem services. Biodivers. Conserv. 2016, 25, 1207-1214. [CrossRef]

(C) 2017 by the authors. Licensee MDPI, Basel, Switzerland. This article is an open access article distributed under the terms and conditions of the Creative Commons Attribution (CC BY) license (http://creativecommons.org/licenses/by/4.0/). 